\title{
Temor, silencio y deliberación: la inhibición de la opinión en Tucídides
}

\author{
Laura SANCHO ROCHER \\ Universidad de Zaragoza \\ 1sancho@unizar.es
}

Recibido: 10 de noviembre de 2014

Aceptado: 26 de noviembre de 2014

\section{RESUMEN}

Tucídides es una de nuestras mejores fuentes de información para conocer la práctica argumentativa de la deliberación democrática. En este trabajo se analiza uno de los vicios que, según el historiador, haría su aparición en la escena política ateniense a la muerte de Pericles: la instrumentalización del miedo para obtener la victoria momentánea en la asamblea. El temor prudente, que fuera una arma periclea para conducir la deliberación racional en aras del bien común, habría desaparecido siendo sustituido por el amedrentamiento del rival, la calumnia, el obstruccionismo y la parálisis de la confrontación dialéctica. Instauradas en la ciudad la desconfianza y la sospecha de ocultación, los golpistas del 411 hallaron el terreno abonado para callar las voces contrarias y, gracias al silencio, instaurar el terror.

Palabras clave: Deliberación. Miedo. Mentira. Ocultación. Inhibición. Silencio. Griterío.

\section{Fear, Silence, and Deliberation: The Inhibition of Opinion in Thucydides}

\begin{abstract}
Thucydides is considered one of the best sources of information about the argumentative practice at work in democratic deliberation. In this paper, I analyze one of the vices that, according to the historian, would appear in the political scene once Pericles died: the exploitation of fear to obtain momentary victory in the Assembly. One of Pericles' devices was to incite some kind of sensible fear in his audience. With it, the Athenian politician hoped to direct deliberation in the interest of the common good. After Pericles' death, Thucydides bear witness to the substitution of dialectical and open confrontations by practices that involved intimidation of the opponent, calumnies or obstructionism. As the historian says, once mistrust and suspicion took hold of the citizens, the coup d'etat 411 members found it very easy to silence the opposing voices and so, establish a state of terror.
\end{abstract}

Key words: Deliberation. Fear. Lie. Occultation. Inhibition. Silence. Shouting.

Sumario: 1. Introducción. 2. La interacción líder-multitud y el miedo recíproco. 3. Desconfianza, calumnia y temor a pronunciarse con franqueza. 4. Conclusión. 


\section{Introducción*}

El temor o miedo, en la medida en que está presente en las deliberaciones de los colectivos implicados en los procesos bélicos, es un factor esencial de explicación en la concepción tucidídea del acontecer histórico. ${ }^{1}$ Los especialistas se han plan-

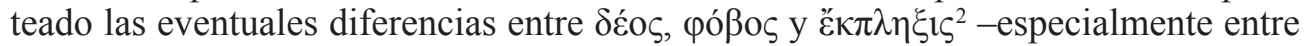
los dos primeros términos-, así como el peso del ingrediente del miedo en el seno de las complejas nociones de naturaleza humana y tò anthrópinon, o la influencia del azar en su desencadenamiento. ${ }^{3}$ La presencia del temor es muy recurrente en las coyunturas de toma de decisión. El proyecto de construir una historia retórica, y los momentos resolutivos plasmados en la Historia de Tucídides, no serían una realidad sin la elaboración de un aspecto tan importante en la psicología de masas como el de las acciones o reacciones inspiradas por el temor.

No es mi intención plantear aquí de forma global la cuestión del miedo en Tucídides ya que, además de ser un asunto demasiado amplio, ha recibido un tratamiento profundo por parte de muchos estudiosos, y monográfico recientemente. ${ }^{4} \mathrm{Mi}$ interés se va a centrar exclusivamente en un aspecto que tiene que ver con la retórica y las decisiones asamblearias; me refiero al temor suscitado intencionalmente por los ora-

\footnotetext{
* Trabajo realizado en el marco del Proyecto HAR2011-26191. Una primera versión de este estudio fue presentada en el curso Miedo e incertidumbre en el mundo antiguo: aproximaciones multidisciplinares a los terrores individuales y colectivos de la Antigüedad, coordinado por la Prof ${ }^{a}$ Silvia Alfayé y celebrado en Jaca (Universidad de Zaragoza) los días 11 y 12 de julio de 2014. Los pasajes de la Historia de la Guerra del Peloponeso incluidos en el texto están tomados de la traducción de Torres Esbarranch $(B C G)$ aunque, a veces, ligeramente modificados. Todas las fechas que aparecen en el texto son a.C.

1 Desmond (2006, 359-360) llega a afirmar que toda la Historia es una meditación sobre el miedo, y una obra escéptica y pesimista que aboga por la circunspección y la duda ante la realidad. HunTER $(1986,415-421)$ también sostiene que el "temor" es el aspecto psicológico más explotado por Tucídides, autor muy influido por Gorgias en este terreno.

2 Muy sucinta e interesante es la exposición de NAGY (2010). Es tradicional y conocida la diferenciación

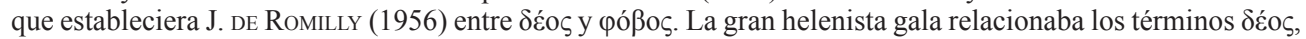
$\delta \varepsilon i ́ \delta \varepsilon \imath v$ con los verbos de pensamiento, por tanto deducía que estarían ligados a la idea de futuro, mientras

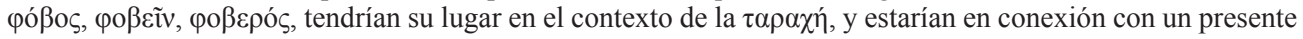
sorpresivo. Cf. HuART 1968, 122 y ss. y PATERA 2013, 122, en sentido parecido. Sin embargo, en la práctica, no se puede hacer una diferenciación neta, salvo en el caso de la $\check{\kappa} \kappa \pi \lambda \eta \xi$ $\iota$ que implica casi siempre terror paralizante ante lo imprevisto y, por ende, sorpresa.

3 Cf. Stahl 1966, 29, quien señala que en Tucídides la ambición de poder y el temor son motivos invariables de la causación histórica. Este estudioso hace hincapié en lo irracional del comportamiento humano al que, además, se une el azar (cf. p.e. 77-79; 98; 111). CogAn (1981, 188-193) matiza la diferencia entre naturaleza humana y $\tau$ ò $\alpha \dot{v} \theta \rho \omega ́ \pi ı v o v$, correspondiendo a este último concepto las acciones sociales y las ideologías, las

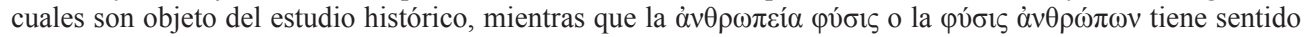
meramente biológico o es la naturaleza humana: emociones, prejuicios, opiniones derivadas de nuestro ser biológico. Mittelstadt $(1985,67 ; 69)$ recuerda que Tucídides nunca refiere un rasgo moral positivo en relación con la naturaleza humana, si bien esta no explica todo el acontecer histórico. Lo malo es que la gnóme le sirve al hombre, esencialmente, para racionalizar su ansia de poder. Wensveen $(2013,43)$ hace un estudio comparativo de los conceptos de naturaleza humana de Hobbes y Tucídides que le permite concluir que en Tucídides la naturaleza está abierta a la razón y no es mecánica. Para el tema del azar sigue siendo fundamental EDMunds $(1975,75,147)$ quien argumenta que, según Tucídides, la acción basada en el conocimiento reduciría la influencia del azar (el cual, a pesar de todo, gobierna la vida), y que el historiador ateniense se ve a sí mismo como alguien que es capaz de diferenciar entre lo ocurrido según una causa y lo que sucede azarosamente.

4 Desmond 2006; Calabrese 2008.
} 
dores y por las masas en las deliberaciones a fin de condicionar las decisiones. Los políticos se sirven de técnicas de amedrentamiento dirigidas a la audiencia y a los oradores rivales con resultados a veces benéficos para la polis, otras, desastrosos. Se trata de un asunto que no ha sido objeto todavía de un estudio particular, ${ }^{5} \sin$ embargo es un fenómeno del que nuestro historiador era bien consciente y que influye en la calidad de las resoluciones tomadas en cada momento.

Según la formulación del ideal de deliberación democrática, las mejores decisiones surgen del debate abierto, de la contraposición y complementación de opiniones y argumentos, de las aportaciones que hacen los ciudadanos al debate común. De ahí que la isegoría -igualdad de acceso a la palabra pública- e incluso la parresía-franqueza que caracteriza ciertos mensajes- sean encomiadas por los oradores atenienses como fundamento de un sistema político igualitario y libre. ${ }^{6}$ Algunos estudiosos recientemente han apuntado, incluso, la idea de que la respuesta de las masas en forma de thórybos (griterío, desorden) constituye una parte indisociable de ese debate abierto, debido a que la mayoría, incapaz de expresarse con un discurso ordenado y persuasivo, precisa recurrir al abucheo, o al alboroto, para hacerse oír por, e imponerse a sus líderes; e incluso para hacer callar a aquellos oradores que le desagradan. ${ }^{7}$ No obstante, no debe olvidarse que las reacciones de las masas a veces no son tan espontáneas como parecen pensar muchos intérpretes modernos, y que los mensajes de ciertos políticos sirven de detonante para el estallido de una parte de la audiencia, la cual no necesita ser mayoritaria para imponerse. Considerado el asunto desde la óptica de las condiciones del debate asambleario, hay que recordar asimismo que la calidad persuasiva de un discurso no asegura que sea verdadero (cf. Th. V 85), y que la sinceridad $\mathrm{u}$ honestidad de un orador tampoco garantiza el triunfo de sus argumentos. La sospecha de ocultación y la conciencia del peso del azar contribuyen también a generar miedo hacia y entre oradores. Reconocer la amenaza del thórybos para la correcta deliberación -como hacen numerosos autores que fueron testigos del fenómeno- no implica tomar posición a favor de soluciones de carácter oligárquico o del gobierno de los expertos. ${ }^{8}$ Significa tan solo señalar un vicio en el que puede incurrir la democracia populista.

5 Desmond $(2006,364)$ señala muy de pasada que en democracia la ausencia de temor está asociada a la $\pi \alpha \rho \rho \eta \sigma i ́ \alpha$.

6 Spina 1986, 28-39; SAXonhouse 2006, 29; 85-99. A pesar del ideal de igualdad, ya FinLey (1962) en un estudio clásico señalaba que el orador en la democracia ateniense era un elemento estructural imprescindible para el funcionamiento democrático; y CANFORA $(2014,91-92)$ hace hincapié en que en las asambleas hablan los que saben hacerlo.

7 SPINA (1986, 66-68) lo califica de "forma de intolerancia". Mara (1993) razona que una democracia que se limitara a canalizar las voces, o los gritos, de los diferentes intereses se alejaría del bien común. Para TACON $(2001,188)$, el $\theta$ ópoßos no necesariamente convierte a la democracia en tiranía del pueblo, sino que refuerza la idea de participación. RoISMAN $(2004,264-6)$ reconoce el potencial intimidador de la masa pero también afirma que las interrupciones pueden ser la expresión legítima de la parresía; de la misma opinión es VilLACĖQue 2013, 296-303. Wallace, además, subraya que solo los sistemas autoritarios hacen callar a las masas (WALLACE 2004, 225-6). Más crítico con el thórybos es BALOT 2004, 244-246.

8 Con esto quiero referirme a la diferencia que hace Ober entre la práctica democrática ateniense y la preferencia platónica o republicana por el gobierno de expertos (ОвеR 2013, 386-388). El pensamiento democrático moderno se contentaría, dice, con que los expertos tuvieran en cuenta la opinión de los no expertos. Cf. GIRARD 2013, 462-464, para una crítica ponderada de las optimistas tesis de Ober. Es bien conocido que 
En las páginas que siguen abordaré este interesante problema a través de luna lectura de la Historia de Tucídides con el objetivo de reflejar las dificultades de la deliberación que, además de ser democrática, requiere alcanzar buenas resoluciones y lograr el mayor grado de seguridad para la comunidad.

\section{La interacción líder-multitud y el miedo recíproco}

Resulta obligado considerar en primer lugar la figura de Pericles como paradigma de líder democrático, o para ser más exactos, reflexionar sobre el retrato que del gran político del s. V hizo Tucídides. ${ }^{9}$ En el famoso capítulo 65 del libro II, Pericles además de tener capacidad de previsión, ser patriota e incorruptible, es descrito como hombre carismático, capaz de inspirar el temor en un colectivo excesivamente confiado, o de trasladar confianza a una asamblea sumida en el pánico. Evidentemente lo que el historiador quiere es plasmar las habilidades retóricas del gran líder; y, más allá de eso, esbozar su superioridad sobre la masa y dejar constancia del correcto uso que de ese dominio hacía como orador. ${ }^{10}$

Veamos el pasaje concreto:

(II 65,8$) \ldots$ aquel, poderoso a causa de su prestigio y su intelecto, y siendo además

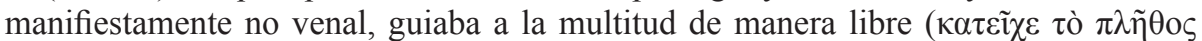

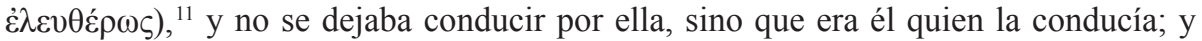
eso era así porque al no haber adquirido el poder por medios ilícitos, no hablaba para

OBER $(1989,1996)$ ha manifestado repetidas veces $-\mathrm{y}$ ha sido muy criticado por ello (cf. por ejemplo RosE 2006) - la convicción de que si el demos ejercía el poder era gracias a que supo imponer su ideología. Por el contrario, CANFORA (2014, passim), que no confía mucho en el criterio de la multitud e ironiza sobre los tópoi de la propaganda popular, interpreta la democracia ateniense como un pacto tácito entre pueblo y elite, en el que buena parte de la aristocracia participa porque obtiene más beneficios que las clases populares. No obstante, no me ocupo en este momento de si la muchedumbre no experta era la que de hecho gobernaba, o de si era mejor gobernante que los supuestos expertos, sino de uno de los mecanismos utilizados frecuentemente, según Tucídides, para impedir el debate abierto.

9 Mitchell sostiene que el Pericles de Tucídides, como el Teseo de Eurípides, son "monarcas" democráticos: figuras que permiten plantear el debate del papel del líder en una democracia (MitcheLL 2008, 2, 14-19, 19). Según esta estudiosa, Tucídides introduciría por esa vía su crítica a la democracia. CANFORA (2014, 122 y ss. y 276) ha subrayado recientemente cómo Tucídides interpretaba en Pericles a un princeps, una figura quasi monárquica. El historiador ateniense pensaría, según Canfora, que un princeps podría ser la solución al dilema democracia versus oligarquía. En vida, no obstante, el político real fue objeto de críticas acérrimas, y no solo desde posiciones oligárquicas: cf. BANFI 2003, 4-70.

10 Cf. Bedford - Workman 2001, 57-58

11 Para Greenwood el significado de esta frase es que Pericles actuaba con plena libertad, lo que implicaba que la masa carecía de ella (GREENWOOD 2004, 184-185). Yunis, por el contrario, cree que Tucídides se refiere al hecho de que Pericles sabía explicar los problemas y no sustituía esa instrucción por habilidades retóricas (YunIS 1991, 182-184; ID. 1996, 69). También Tsakmakis dice que Pericles pretendía racionalizar la acción colectiva y hacer de la masa una totalidad de individuos responsables (TsAKMAKIs 2006, 168). LEBOW (2007) plantea un interesante dilema: un exceso de razón puede ser derrotado cuando no se tienen en cuenta las emociones y los deseos. Así ocurre con Pericles, que encarna la racionalidad en Atenas, pero que, a tenor de la respuesta de Corinto en la guerra de Corcira, habría calculado mal su propia estrategia disuasoria frente a la fuerza de la humillación sentida por Corinto. 


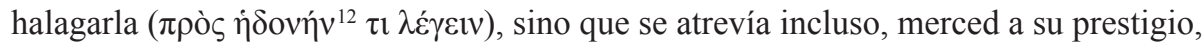
a enfrentarse a su enojo ( $\pi \rho$ ò $\varsigma$ ópүív). (9) Así, siempre que los veía confiados de modo

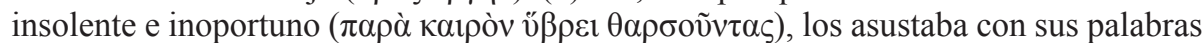

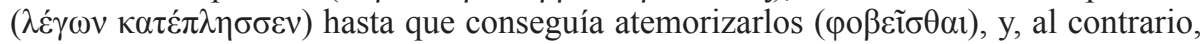
cuando los veía atemorizados sin razón ( $\delta \varepsilon \delta i ́ o \tau \alpha \varsigma \alpha ̉ \lambda o ́ \gamma \omega \varsigma)$, los hacía retornar a la confianza ( $\tau$ ò $\theta \alpha \rho \sigma \varepsilon i ̃ v) .{ }^{13}$

De la lectura de este pasaje podemos deducir en qué medida un demagogós lo es en el pleno sentido -el etimológico y no peyorativo- del término si posee habilidad retórica para producir en su auditorio los estados de ánimo convenientes, y si su honestidad e inteligencia políticas procuran que las emociones estén caracterizadas por la contención y sirvan de vehículo a la razón. ${ }^{14}$ El miedo irracional o la soberbia confiada son estados psicológicos incompatibles con la deliberación sensata porque desvían las mentes de un análisis racional de la situación. Cuando Tucídides introduce este capítulo apologético, a la muerte de Pericles, los atenienses ya habían tenido una reacción visceral en contra del Alcmeónida y de su estrategia de guerra, a pesar de que previamente la habían aprobado aconsejados por él (II 61, 2; cf. I 145). Pericles había previsto esa reacción porque sabía que los peloponesios invadirían el Ática y arrasarían las fincas de muchos ciudadanos y, a pesar de ello, se aferraba al plan de no salir a dar batalla campal, y mantenía su confianza en las posibilidades de que Atenas venciera a sus enemigos, siempre que los atenienses supieran jugar bien sus bazas, fueran conscientes del valor de lo que tenían y estuvieran dispuestos a defenderlo del modo más inteligente. Lo único que no pudo prever fue el desencadenamiento de la epidemia (II 61,3), aunque sí advirtió que era necesario limitar en la medida de lo posible la capacidad de influencia del azar (Cf. I 144, 4).

Los atenienses, ante las primeras vicisitudes de la guerra, estaban consternados (II 62,1$)$ y habían cambiado de opinión $(59,1$; cf. I 145) a raíz de cómo el conflicto les afectaba particularmente, por eso abandonaban la consideración del bien común, único según Pericles capaz de salvaguardar el privado. Finalmente, a pesar de su reticencia inicial (II 22, 1), Pericles reunió la asamblea para transmitirle tranquilidad, confianza, sensación de seguridad $(59,3 ; 62,4-5) .{ }^{15}$ Dado que Tucídides se esforzó en plasmar el grado de irritación de las masas y recalcó, como hemos podido com-

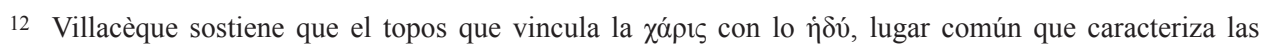
relaciones entre orador y auditorio, podía ser empleado en contra del primero para acusarlo de buscar agradar al pueblo ocultándole la realidad (VILlacėQue 2013, 292-293) Pericles, al contrario que los que vinieron

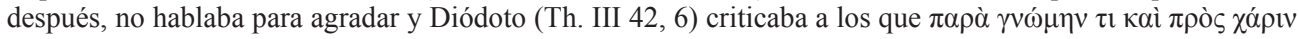
$\lambda \varepsilon ́ \gamma o 1$, aunque consideraba que el demos tenía bastante responsabilidad en ello (infra).

13 También Aristóteles (Rhet. 1383a 5-12) aconseja inducir al auditorio al miedo si esto es conveniente para la deliberación, porque se delibera cuando hay esperanza de salvación y temor a perder lo que se tiene. Del mismo modo, la confianza se recobra gracias a la conciencia de tener suficientes medios humanos y económicos para hacer frente a los peligros (1383a 35-b2). Patera comenta que cuando se trata de una muchedumbre, la cual experimenta las emociones como si fuera un solo hombre, el lógos de uno es el que las orquesta, y ese uno es el hombre superior que controla sus estados de ánimo (PATERA 2013, 119, 130-131).

14 Sobre la relación entre estados emocionales y procesos de deliberación, cf. VISVARDi 2012.

15 Comenta Bassi que si Pericles permanece en la misma opinión, su actitud se corresponde con la imagen de una Atenas atemporal que él mismo, en la oración fúnebre, elabora (BASsi 2007, 200). Con este recurso literario, el autor anunciaría desde el inicio la derrota y destrucción de la Atenas periclea. 
probar en el pasaje arriba citado, que Pericles era capaz de insuflar confianza cuando la multitud estaba aterrorizada, podemos imaginar que el Alcmeónida tuvo que hacer frente, en la mencionada asamblea, al vocerío de la multitud, y que logró devolverle la calma (cf. 22, 1). Porque Pericles es presentado en Tucídides como un hombre en el que la razón no cede espacio al temor irreflexivo.

Un miedo prudente ayuda a tomar decisiones correctas, pero el terror irracional paraliza la mente y conduce a errores similares a aquellos que inspira una insensata confianza. Como Yunis ha argumentado, ${ }^{16}$ los discursos de Pericles son didácticos, instructivos: desvelan ante la audiencia las consecuencias de las cesiones (I 140,5) y su significación (II 62, 2-3), y ponen de manifiesto los recursos con los que puede contar Atenas para vencer, y las condiciones que es necesario respetar para esa victoria. Pericles no era solo un perito en la técnica de la retórica, un hombre dotado para la persuasión. Además de serlo, no engañaba a los ciudadanos y estos lo respetaban. ${ }^{17}$ Tal vez algunas de las declaraciones que el historiador atribuye al político no resultarían aceptables para el gusto actual, pues los ciudadanos modernos estamos poco dispuestos a que se nos recuerden las implicaciones que llevan aparejadas nuestras demandas. Por eso nos choca ver la transparencia con la que Pericles habla del poder y de la hegemonía atenienses, de sus servidumbres y ventajas; un lenguaje que no ocultaba en modo alguno la crudeza de las relaciones internacionales. ${ }^{18}$ Tucídides insiste en que Pericles no hablaba para halagar sino para hacer responsables (II 61,2) a los ciudadanos de las opciones por las que se decantaban, y para plantearles las consecuencias que acarreaban las mismas. El temor que Pericles intentaba infundir en los ciudadanos -si abandonaban el arché- era el adecuado para contrarrestar un exceso de confianza -si creían que no tendrían que pasar penalidades para mantenerlo- que sería contrario a la asunción de obligaciones. Pero cuando del temor se pasaba a la consternación (II 62,1), y a una ceguera que impedía valorar las razones por las que Atenas no había cedido a las exigencias espartanas, entonces convenía inspirar en los ciudadanos una cierta seguridad basada en argumentos (§ 4-5). Esa era la manera de actuar de Pericles de cara a los atenienses, pues a los ciudadanos los consideraba dignos de ser tratados como seres racionales. Pero, como se oponía a que se hicieran concesiones al enemigo (I 127, 2), animaba a responder en términos parejos a los que los adversarios empleaban. Cuando los peloponesios decidieron difundir en Atenas los escrúpulos religiosos, derivados del sacrilegio antiguo de los Alcmeónidas, con el fin claro de que los atenienses culparan a Pericles de la epidemia que les sobrevenía,

16 YUNIS 1991, 185; ID. 1996, 76.

17 Zumbrunnen es pesimista acerca de la posibilidad de que el dêmos tenga capacidad de formarse una opinión, e interpreta el silencio de las asambleas en las que solo habla Pericles como ausencia de deliberación racional (ZUMBRUNNEN 2008, 6-17). La unidad de acción atribuida a "los atenienses", por otra parte, sería tan solo el resultado de la forma de percibirse a sí mismos que los líderes confieren al pueblo. También Hunter argumenta que Tucídides asume la visión gorgiana del lógos como capaz de evocar todo tipo de estados emocionales más que de ayudar al razonamiento y la reflexión (HunTER 1986, 421-427); tal vez por ello para

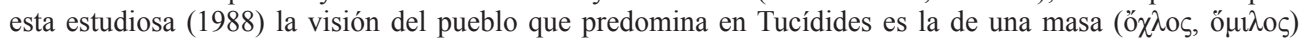
cuya acción es mayormente espontánea e inarticulada. Cf. Verdenius 1981, 124-125: Gorgias se inspiraría en Parménides para establecer la diferencia entre lógos-razón, vehículo de la verdad, y lógos-palabra, representación de la apariencia.

18 ZuMBRUNNEN 2008, 133-134. 
estos, tal vez aleccionados por el mismo Alcmeónida, replicaron recordando a los lacedemonios el sacrilegio de Ténaro y el de Atenea Calcieco (I 127 1; 128, 1-2). Y esta respuesta debió de ser más efectiva en terreno espartano que el recuerdo, en el campo ateniense, del asesinato de Cilón por el arconte Alcmeónida de 632 a.C., pues es conocido que los espartíatas se sintieron siempre aprensivos por ser los responsables de haber roto el tratado de 446 (cf. I 123, 2).

Los sucesores de Pericles ${ }^{19}$-adelantaba Tucídides ya en II 65, 10-11- fueron inferiores a él, más iguales entre sí, e incapaces de erigirse en guías del demos. Por el contrario, iban detrás del pueblo, e intentaban congraciárselo diciéndole lo que este quería oír. Por tanto, podría decirse que temían al demos, algo que en absoluto se percibe en Pericles. Cabe preguntarse si esta mutación del liderazgo popular es real o solo es producto del empeño de Tucídides por idealizar a Pericles. Tal vez las circunstancias bélicas expliquen el deterioro de la vida pública y, con ello, la metamorfosis de la relación entre la multitud y sus dirigentes. ${ }^{20}$ Dos pasajes apuntan de manera general hacia una degradación de las relaciones sociales en términos éticos. ${ }^{21}$ El primero describe la inversión moral que se produce como efecto de la enfermedad física, de la epidemia (II 49-53);22 el segundo vincula el declive de las convenciones sociales y su resultado, la stásis, con la contienda internacional. ${ }^{23}$ En concreto, nos interesa sobre todo recordar que nuestro autor se detiene especialmente en los efectos de la stásis sobre la manipulación del lenguaje (III 82, 4), ${ }^{24}$ porque eso remite a la inseguridad acerca del contenido del mensaje, algo que haría desconfiar a todos de todos $\mathrm{y}$, en consecuencia, empujaría a cada uno a buscar su salvación particular, adelantándose a los delitos de los demás. ${ }^{25}$ En todo caso, en la Historia se retrata varios escenarios en los que los políticos aparecen como figuras mediocres e incapaces de hacer valer sus argumentos, en el caso de que los tengan, ante la asamblea.

Así ocurre en 425 a.C. con Cleón, quien, a pesar de todo, es presentado como

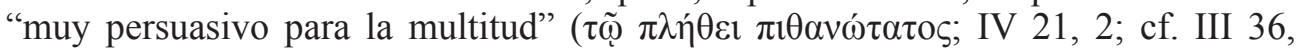

19 ConNor (1971) denominó “nuevos políticos” a los pertenecientes a la generación postpericlea, caracterizados por que su extracción social ya no era aristocrática, y por la tendencia a especializarse como oradores.

20 Yunis 1996, 88 y ss.; BedFord - Workman 2001, 59-61; Zumbrunnen 2008, 68.

21 Romilly enumera la epidemia, la stásis de Corcira y el diálogo melio como tres pasajes que en Tucídides establecen la diacronía de la decadencia moral (De RomiLly 1977, 87-98).

22 Morgan (1994) considera que la descripción desordenada de síntomas y comportamientos tiene fines más poéticos y morales que fácticos o científicos. Cf. Wensveen 2013, 51-52, sobre los pasajes que Tucídides consagró a la enfermedad y a la stásis que, aunque sirvieron de inspiración a Hobbes, dejan ver que en el clima de miedo generado por el desorden, y a pesar de la ansiedad general, persisten comportamientos virtuosos, honorables, compasivos o piadosos, que demostrarían que en Tucídides la capacidad humana para la justicia era también natural.

23 LORAUX 1986, 100.

24 Cf. Loraux 1986, 102, quien traduce la frase de III 82, 4, como "cambiaron hasta el sentido habitual de los términos", con el objetivo - comenta- de cambiar la relación de las palabras con los actos dando a estos nombres nuevos. Solmsen habla de un cambio en la "reputación" de los términos, un cambio relativo a una situación política y moral nueva (SOLMSEN 1971, 395-396).

25 Cf. BEDFORD - Workman 2001, 59-61: la degeneración del lenguaje liberaría a la acción de la deliberación. Muy acertadamente Calabrese califica la situación descrita en III 82 como de "violencia inmanente" (CALABRESE 2008, 65). 
6). Cleón maniobró para que Atenas no negociara con Esparta un acuerdo a cambio de levantar el bloqueo de Esfacteria (IV 22, 2). ${ }^{26} \mathrm{Al}$ parecer, la razón de fondo era que esperaba obtener más si presionaba a los enemigos pero, como ulteriormente la posición de Atenas en Pilos se estancó, Cleón empezó a temer su caída en desgracia ante las masas ${ }^{27}$ y para ponerlas de su lado decidió desprestigiar a los embajadores que traían las noticias de Pilos. Dijo que mentían $(27,3)$ y, a la vez, exhortó a Nicias, que era uno de los estrategos, a emprender una expedición contra la isla. El poder de la multitud sobre este político y la dependencia que, de ella, sentía Cleón se evidenció cuando Nicias, inesperadamente, le cedió el mando. Entonces la asamblea jaleó a Cleón para que lo aceptara y él, temeroso ( $\delta \varepsilon \delta 1 \omega ́ \varsigma)$, no vio otra salida que asumirlo $(28,2-3)$. Podemos reconstruir una secuencia de imágenes en las que este demagogo ${ }^{28}$-ahora en el sentido moderno y peyorativo del término (cf. IV 21, 3)-, amedrentado al ser pillado en su propia trampa, se vio obligado a asumir su particular órdago: tomar Esfacteria en veinte días. La presión que sobre él ejerció el thórybos, el disgusto y griterío de la muchedumbre ( $\dot{\varepsilon} \pi \varepsilon \beta 0 \omega ́ v)$, y también las risas ( $\gamma \varepsilon \dot{\varepsilon} \mathrm{o} \sigma \omega \varsigma$; $\S 5)$ de las masas, pudieron ser una muestra de democracia, pero desde luego no lo fueron de sensatez. Si las cosas finalmente le salieron bien a Cleón y a Atenas $(39,3)$, fue por azar y porque Demóstenes, el general que permanecía in situ, ya había elaborado un plan al que intentaba dar cumplimiento $(29,1)$. Hay que añadir que aquellos que, seguramente por miedo, no osaban enfrentarse verbalmente en la asamblea a un

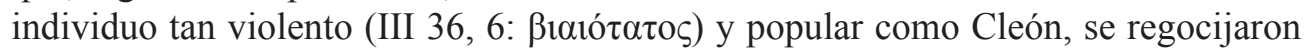
de verlo alejarse y de la posibilidad de que no regresara (IV 28, 5). Tucídides los describe como sensatos ( $\tau$ oĩ $\sigma \omega ́ \varphi \rho o \sigma \iota ~ \tau \tilde{\omega} v \dot{\alpha} v \theta \rho \omega ́ \pi \omega v)^{29}$ y, desde mi punto de vista, representan a cuantos se inhibían en asambleas que controlaban políticos lenguaraces del tipo que encarna Cleón. En suma, Cleón temía a la multitud, y la minoría temía al político más popular del momento: y, en consecuencia, ni el primero, ni los últimos actuaban o hablaban con franqueza.

Una circunstancia semejante se dio en 415 ante el asunto de la expedición a Sicilia. Cuando ya había sido votada la ayuda a Egesta - propugnada por Alcibíades, quien en este momento era el demagogo más popular-, Nicias volvió a sacar el tema con la intención de revertir la anterior decisión. Hay que subrayar la osadía de Nicias, amparada seguramente en el prestigio que le otorgaba ser el general que había sellado

26 Lafargue argumenta que Cleón no exigía nada descabellado pues era Esparta quien entonces estaba derrotada, y que los puertos reclamados: Nisea y Pegas en Mégara, y Trezén en Acaya, estaban en posesión de Atenas en 446/5 (Lafargue 2013, 55-56). En relación con el papel de Cleón cuando el alargamiento de la situación ateniense en Pilos la hacía insostenible, Lafargue cree que Tucídides "semble y perdre sa réserve habituelle".

27 Tsakmakis considera que Cleón sufre el desprecio de la audiencia, como Hermócrates en el discurso de 415 en Siracusa (Tsakmakis 2006, 166-167). Un político efectivo sería el que previera la reacción de la multitud y se anticipara a ella como Pericles. Los ciudadanos prudentes recordarían, según Tsakmakis (2006, 170), lo que Cleón había dicho en 427 acerca de la gente preparada.

28 Se puede leer en CANFORA 1994 un pequeño ensayo sobre la evolución del concepto hasta nuestros días.

29 Demont considera que Nicias intentaba moderar la democracia asociado a estos "prudentes" y que esa tendencia seguía viva en el proyecto oligárquico de 411 (DEMONT 1990, 242-248). 
la paz de 421. Su discurso, ${ }^{30}$ no obstante, tuvo un tono defensivo, sirviéndose de argumentos del tipo siguiente: también son buenos ciudadanos los que no desean la guerra; esta paz no es segura; corremos el riesgo de que de nuevo se desencadene aquí el conflicto... Todas sus consideraciones eran indicio de que Nicias esperaba el rechazo de su planteamiento, porque temía la fortaleza de la posición de Alcibíades. ${ }^{31}$ Nicias carecía de la confianza en sus propias razones que sí poseía Pericles. Pero tal vez su mayor equivocación fuera intentar infundir en las masas la sospecha hacia Alcibíades al que, al igual que a otros "jóvenes", acusó de moverse por intereses particulares, fomentando con eso la división de la ciudad. ${ }^{32}$ Él mismo reconoció tenerles miedo ( bíades temían hacerse notar (ibid. y 24, 4). Es verdad que Tucídides dice que algunos hablaron en contra de la expedición (VI 15), pero en general el historiador apunta a individuos anónimos que callaban, por miedo a parecer "mal dispuestos hacia la ciu-

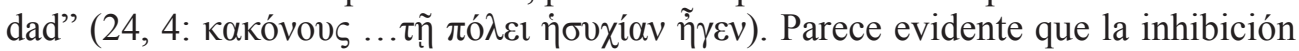
de la opinión se daba especialmente entre ciudadanos que no solían hablar en público y que temían incluso que se les recriminara no compartir la euforia comunitaria. Esa escasa disposición a manifestarse públicamente era consecuencia de sentir la presión de las masas -comprensible si recordamos el entusiasmo con el que se despidió a la armada (30-31)-, así como del lenguaje que seguramente emplearon los partidarios de la campaña. Cuando Alcibíades apeló a las virtudes tradicionales de los atenienses: la constante actividad y la unión en la acción de todos los grupos de la polis (cf.

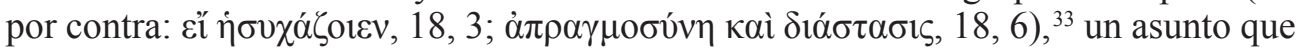
poco tenía que ver con la oportunidad de esta guerra, el objetivo buscado, como sospechó Nicias, era que los contrarios a la expedición fueran vistos como antipatriotas

30 Sobre las inhabilidades retóricas y la incapacidad de captar el kairós de Nicias, cf. SHANSKE 2007, 59. En el contexto de la preparación de la expedición y la antilogía de Nicias-Alcibíades se plantea muy en concreto el espinoso asunto del "conocimiento democrático". Cf. SмIтн 2004, 36-38, 44-47, 57, al respecto. Tucídides afirma que los atenienses desconocían todo sobre la isla, pero eso no es totalmente cierto. La información del historiador en la Arqueología, en todo caso, tampoco contribuye a aclarar la relación de fuerzas del momento. Los atenienses poseían tal vez un conocimiento tópico basado en la retórica, los dramas y las conversaciones; $\mathrm{y}$, por su parte, el historiador elabora de cara al lector la situación dramática en la que, partiendo de la apeiría democrática, se presiente el desastre.

31 Tsakmakis comenta que Nicias interviene siempre a destiempo (TsAKMAKIs 2006, 171). Calabrese supone que Nicias, como Atenágoras (infra), también habría sugerido que su rival y los jóvenes que lo rodeaban eran filo-oligarcas pero lo habría hecho de manera muy sutil (VI 11, 7; 12, 2); (CALABRESE 2008, 149-150). De ser así, ¿se trataría de mera calumnia o sus palabras se basaban en esa percepción generalizada que, acerca de Alcibíades, parecen haber compartido muchos atenienses, según sugiere el mismo Tucídides $(15,4)$ ?

32 ZumbrunNen 2008, 116-117.

33 Cf. Huart 1968, 367-373. MacLeod afirma que el razonamiento de Alcibíades es persuasivo porque apela a la tradición de la ciudad a la vez que a la necesidad (MACLEod 1983, 83). Demont recuerda que en este aspecto el discurso de Alcibíades retoma en esencia al de Pericles: no se puede abandonar un imperio (Demont 1990, 241). Saxonhouse apunta que Alcibíades no conoce mejor la situación de Sicilia pero sí el carácter ateniense (SAXONHOUSE 2006, 170-171). Zumbrunnen sostiene que los oradores tratan de inculcar en la audiencia la idea de que lo que la ciudad hizo en el pasado refleja un modo de actuar que debería guiar el futuro (ZuMBRUNNEN 2008, 85). También Bassi señala que la imagen de continua actividad a la que recurre Alcibíades es la misma imagen de la Atenas eterna que elabora Pericles (BAssi 2007, 201-206). Sin embargo, en la última parte de la Historia, se ilustraría el problema de la inexistencia de esa Atenas (su recuperación por Alcibíades, su regreso) y la inadecuación del cliché de los trópoi para explicar el acontecer. 
o, directamente, antidemócratas. Por eso Nicias en su primer discurso, frente a los jóvenes que rodeaban a Alcibíades, apeló especialmente a los hombres de edad entre los que esperaba encontrar apoyo; y les exhortó a no avergonzarse temiendo que sus opiniones fueran interpretadas como cobardía, sino que, por el contrario, los animó a

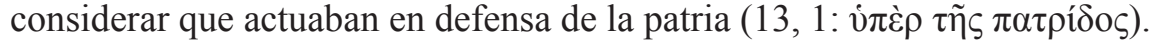

Las palabras de Tucídides retratan una coyuntura política en la que un grupo, el que rodea a Alcibíades, se había apoderado en su beneficio del lenguaje democrático y acusaba a los rivales políticos, no meramente de escasa clarividencia para los asuntos, sino directamente de opuestos al pueblo, de enemigos de la democracia. $\mathrm{Si}$ los que no consideraban conveniente, oportuna o inteligente la campaña de Sicilia no se atrevieron a expresarse a las claras, era por miedo a ser tildados de oligarcas, a ser considerados enemigos de la ciudad.

Así pues, Cleón, que parecía tener tanta ascendencia sobre la multitud, se sometió a la presión de la masa a la que temía. Y Nicias, que no se sentía demasiado a gusto ante la muchedumbre, sucumbió ante las artimañas de un político como Alcibíades que movilizó los sentimientos populares contra él y a favor de los intereses propios.

Finalmente, en el ámbito de la relación líder-multitud, hay que mencionar el asunto de la carta que Nicias envió a la asamblea de Atenas desde Siracusa relatando la cruda situación en la que se encontraba el ejército allí desplazado. Tucídides dice que el estratego recurrió al documento escrito por temor ( $\varphi$ oßov́ $\mu \varepsilon v o \varsigma)$ a que sus palabras exactas fueran tergiversadas en la versión de sus embajadores. La prevención, en este caso, hace referencia a las condiciones retóricas; pues pensó que o los embajadores resultarían ser malos oradores, o podrían tener la tentación de querer agradar al pueblo (VII 8,2). El objetivo de Nicias era que la asamblea conociera la verdad (cf. 14, 4) y deliberara en consecuencia. El miedo de Nicias a los demagogos rivales y a la actitud irresponsable de la masa asamblearia $(48,3-4)$ es lo que le hizo recurrir a una epístola ayuna de retórica, y es una muestra más de la gran diferencia entre Pericles, capaz de guiar al pueblo y de recrear en la asamblea los estados emocionales a voluntad, y sus sucesores, incapaces de pilotar a la multitud y, por tanto, temerosos de las imprevisibles reacciones de esta.

\section{Desconfianza, calumnia y temor a pronunciarse con franqueza}

En el apartado anterior ha quedado ilustrada la diferencia entre una comunicación política transparente y desinhibida, en la que el orador controla los estados emocionales del auditorio y promueve en él un temor prudente que favorece la deliberación, y otra condicionada por la aparición de la coacción psicológica -horizontal y vertical- y caracterizada por el miedo a manifestar abiertamente la posición política individual. Se ha subrayado la importancia de la personalidad de cada líder, pero también se han tenido en cuenta las circunstancias históricas que lo rodean y que influyen negativamente en la comunicación. En esta segunda parte voy a centrarme especialmente en tres situaciones: el debate mitileneo (427), la discusión en la asamblea de Siracusa antes de la llegada de los atenienses (415), y las relaciones políticas en la Atenas del 
golpe de estado de 411. Se trata de escenarios que acompañan al desarrollo bélico, etapas que seguramente Tucídides consideró exempla de la ineluctable degradación de la deliberación política. El objetivo ahora será reflexionar sobre algunos de los motivos que instauran la desconfianza en el trato entre dirigentes, y entre políticos y pueblo. En la medida en que la comunicación pierde franqueza, veremos cómo hacen su aparición la calumnia, la mentira u ocultación y el silencio.

Los discursos enfrentados de Cleón y Diódoto brindan dos visiones contrastadas sobre lo que debiera ser una deliberación eficaz e inteligente. Y lo hacen ofreciendo, no solo una doctrina explícita al respecto, sino también la práctica de dos estilos retóricos antitéticos. Cleón critica a los atenienses por confundir las relaciones entre

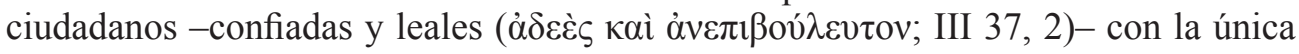
que puede existir en un imperio entre la potencia hegemónica y los súbditos que conspiran contra ella. ${ }^{34}$ La visión de Pericles no era muy diferente $;{ }^{35}$ como he señalado, el Alcmeónida no dejaba de subrayar con crudeza la realidad de las relaciones internacionales. Pero en lo que se diferenciaban Pericles y Cleón era en que el primero no trataba a los asambleístas como hombres mediocres, sino que esperaba que se comportaran como ciudadanos que comprendían la situación y obraban en consecuencia. Cleón, por el contrario, exaltaba el buen gobierno de los hombres vulgares, ignorantes y obedientes a lo que él denomina las leyes, aunque en el caso concreto se refería a la decisión (un pséphisma) por él propugnada y ya aceptada en la asamblea previa. No puede ocultársenos que a Cleón le interesaba cultivar la existencia de ciudadanos pasivos y acríticos -masa antes que ciudadanos- aunque en su discurso se sirviera de argumentos tan elevados y nobles como el de la obediencia a la ley. En consonancia con su llamada a la realidad, se quejaba de que los atenienses acudieran a las asambleas como quien va al teatro o a escuchar las exposiciones en concursos retóricos, ${ }^{36}$ y apelaba a la corresponsabilidad de la ciudadanía en la marcha de la guerra y del imperio. Ahora bien, en lugar de reflexión o deliberación, proponía que las decisiones se tomaran en un clima que cabría calificar de pánico o consternación ("sin olvidar el peligro que entonces pendía sobre vosotros", III 40,7), ${ }^{37}$ situación que propiciaría la irreflexión y la transmutación de una asamblea deliberativa en masa irracional.

Se ha dicho que Diódoto resulta el más pericleo de los políticos de la nueva generación debido a su insistencia en la necesidad de deliberar en profundidad antes de tomar una decisión (III 42, 1; cf. II 40, 2-3). Diódoto sostuvo que era obligatorio recapacitar sobre cuestiones importantes $\mathrm{y}$, aunque seguramente no pretendía que cualquier resolución fuera revisada, admitía que ciertas circunstancias aconsejaban tomarse un tiempo. Lo cierto es que en la Historia hay varios ejemplos de reuniones asamblearias en las que se revisa una decisión previa: en el libro I, el acuerdo de fir-

34 Cf. Shanske 2007, 53-54, quien señala las grandes líneas de continuidad entre Pericles y Cleón, desvela en Diódoto un ataque frontal al clima político de Atenas. Para Diódoto, Atenas "as internal tyranny is an inversion of the Periclean vision...".

35 LAFARGUE 2013, 47-49.

36 VillacèQue 2013, 288 y ss.

37 Como es sabido Cleón argumentó que las mejores decisiones se toman "en caliente", pues la cólera inicial permitiría valorar mejor la injusticia sufrida y, por tanto, vengar de manera proporcional la infracción (cf. Visvardi 2012, 2-3). 
mar una epimachía con Corcira fue resultado de una segunda asamblea; en este libro III, es una segunda asamblea la que resuelve atenuar el castigo de los mitileneos; pero en el VI, la decisión de embarcarse hacia Sicilia sale reforzada tras el debate retomado a instancias de Nicias. Reabrir una deliberación no siempre es posible ni oportuno. Los casos citados recogen tres coyunturas en las que la disyuntiva reclama argumentar en profundidad. En el primero de ellos, a tenor de los discursos de corcireos y corintios, el dilema para los atenienses se cifraba en tomar una decisión que tomara en consideración la inminencia o no de la guerra. La discusión sobre la campaña siciliana se tendría que haber resuelto de manera parecida, tras apreciar pros y contras de reabrir la guerra, pero se convirtió en una pugna personalista entre Nicias y Alcibíades. El segundo discurso de Nicias, pensado para desinflar las expectativas generadas por las soflamas de Alcibíades, consiguió todo lo contrario: transmitir una confianza en la victoria que el propio Nicias no tenía. La ausencia de reflexión, por no haber deliberado en un estado de temor prudente, abocó a los atenienses a la catástrofe. En el caso que nos ocupa, Diódoto, de manera inteligente y persuasiva, desmontó los argumentos de su rival e hizo posible que, en un estado emocional más calmado, los atenienses cambiaran su primera votación.

Si Cleón había sugerido que los que se oponían al castigo ya votado lo hacían por interés personal, apuntando a un más que verosímil soborno de los mitileneos, Diódoto recondujo lo que calificó de calumnia hacia otro terreno, el de si el castigo impuesto beneficiaba o no a Atenas. ${ }^{38}$ En ese contexto sostuvo que los que se oponían a que los argumentos guiaran las acciones lo hacían por creer que iban a ser incapaces de defenderse exitosamente con las palabras y, por tanto, pretendían atemorizar $(\dot{\varepsilon} \kappa \pi \lambda \tilde{\eta} \sigma \alpha \imath)$ a la audiencia y a sus opositores con hábiles calumnias $(42,2)$. El tipo de temor que con esta argucia pretenderían generar perseguía el silencio o retraimiento de las opiniones contrarias. ${ }^{39} \mathrm{~A}$ tenor de las palabras de Diódoto la práctica obstruccionista debía de ser frecuente. Por eso Diódoto exigía que en lugar de amedrentar

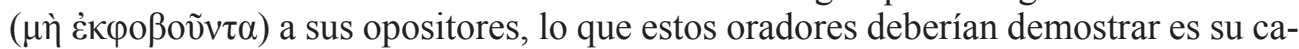
pacidad de ser superiores con los razonamientos (§5). Con este comentario, además, estaba sugiriendo que los que recurrían a usos intimidatorios no tenían argumentos o no sabían exponerlos de manera persuasiva. Si tenemos en cuenta la repetición en pocas líneas de dos verbos que implican terror ( $\dot{\varepsilon} \kappa \varphi \circ \beta \varepsilon \tilde{v} v$ y $\dot{\varepsilon} \kappa \pi \lambda \hat{\varepsilon} \sigma \sigma \varepsilon \imath$ ) y comparamos la práctica criticada por Diódoto con la capacidad de Pericles, según Tucídides, para conducir la correcta deliberación, puede entenderse por qué el historiador dice que Pericles guiaba al demos "con maneras libres". El núcleo mismo de la cuestión es la posibilidad de un debate auténtico, en el que nadie oculte las verdaderas razones que

38 Como sostiene Visvardi, también Diódoto estaba convencido de que los colectivos toman decisiones irracionales movidos por emociones equivocadas, pero este orador se propuso y consiguió transformar la cólera inicial en fría reflexión, al introducir el tema de la utilidad del castigo a los mitileneos para Atenas (VISVARDi 2012, 4).

39 Saxonhouse atribuye a la asamblea la coacción para silenciar a los oradores. Según la estudiosa, mientras Cleón esperaba unanimidad de la asamblea, Diódoto reclamaba la ausencia de presión que permitiera hablar sin miedo (SAXonhouse 2006, 157). Calabrese opina que entre Cleón y Diódoto hay un desacuerdo acerca de si es bueno o no decidir en un estado de miedo (CALABRESE 2008, 114-119). Diódoto sugeriría que era bueno reducir el estado de ansiedad de la mayoría. 
justifican su postura por miedo a ser descalificado, o por temor a perder la consideración social. Según Diódoto eso solo sería posible si el prestigio de buen ciudadano de aquel que toma la palabra no dependiera del coyuntural apoyo popular:

(III 42,6) De este modo será muy difícil que el orador que tenga éxito, con vistas a una consideración todavía mayor, diga algo en contra de sus convicciones para com-

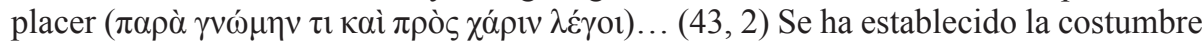

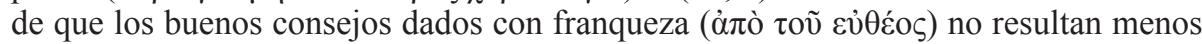

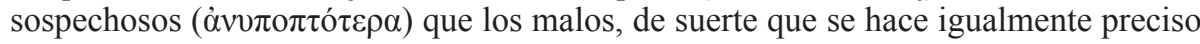
que el orador que quiere hacer aprobar las peores propuestas seduzca al pueblo con el

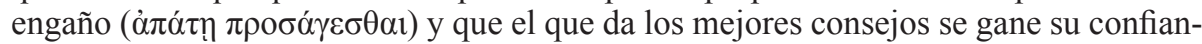
za mintiendo ( $\psi \varepsilon v \sigma \alpha ́ \mu \varepsilon v o v \pi \imath \sigma \tau o ̀ v ~ \gamma \varepsilon v \varepsilon ́ \sigma \theta \alpha \imath)$.

Si estas palabras pronunciadas en 427 reflejaban la realidad del momento, ilustrarían un cambio radical con la época de Pericles porque el hijo de Jantipo, debido a su

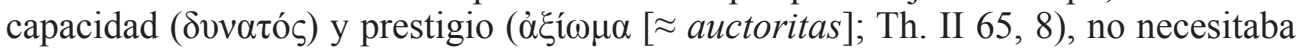
recurrir a engaños. Confiaba en su carisma, pero también en la transparencia y fuerza de su mensaje. Por otra parte, si nos atenemos a la presentación de Tucídides, no parece que en su época la coacción y la calumnia fueran moneda de cambio o instrumento para triunfar sobre los rivales. Cuando la "mentira", en palabras de Diódoto, empezó a acompañar a los buenos y a los malos consejos, la audiencia se acostumbró a desconfiar de todos. Y hacer el bien a la ciudad exigía, según este líder, dominar esa doblez. Por eso se ha esgrimido que, en el fondo, el argumento de utilidad sobre el que se basa Diódoto no es sino otra mentira para evitar una injusticia, el asesinato de todos los mitileneos y la destrucción total de la polis, ${ }^{40}$ un castigo tan desmesurado que todavía horrorizaba a los atenienses aunque nadie se atreviera a criticarlo ante Cleón.

No solo en Atenas se dejaban sentir los efectos de esta perversión que podía desvirtuar el fundamento de la democracia. También en Siracusa, justo en los momentos que precedieron a la llegada de la armada ateniense, se celebró una asamblea en la que se planteó la oportunidad de adelantarse al desembarco de esta en la isla. Tucídides reconstruye, en la forma habitual de antilogía, las dos posturas expuestas en el momento. Hermócrates, un joven general (cf. VI 38, 5) que ya tuvo un protagonismo decisivo en 424, avanzó a la tribuna para informar que estaba en marcha la mencionada invasión y para aconsejar a los siracusanos que se adelantaran a su llegada, que esperaran a los barcos atenienses en Tarento, para dar muestras de decisión y fortaleza $(34,4)$. Hermócrates, como Nicias, sabía que su mensaje no sería fácilmente creíble y afirmó que, por el bien de la ciudad, se había decidido a hablar a pesar del temor

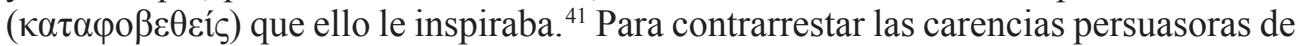

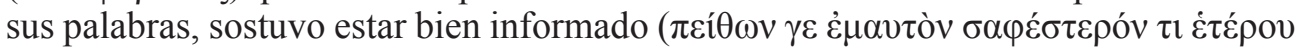

40 Manuwald 1979; Lebow 2007, 180.

41 Yunis $(1996,110)$ opina que Hermócrates hizo un discurso poco persuasivo. SAXonHouse (2006, 173) comenta a tenor de las palabras de Hermócrates que, utilizar un lenguaje franco, no asegura ser creído. Calabrese $(2008,128)$ considera que Atenágoras fundamentó su intervención en la falta de confianza que habría transmitido Hermócrates (VI 35, 1). 


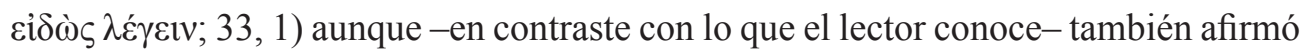
que la flota enemiga no poseía demasiados recursos $(34,5)$. La réplica a Hermócrates la dio Atenágoras, al parecer un demagogo de más edad (cf. 35, 2; 38, 5), quien

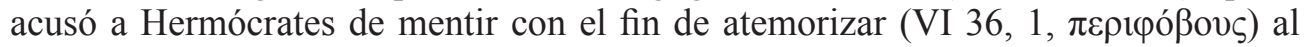
pueblo desviándolo de sus verdaderos intereses. Los primeros párrafos de su discurso pergeñan un escenario de actividades golpistas en el que los "oligarcas", temerosos de ser descubiertos, harían cundir el miedo entre la ciudadanía anunciando una falsa invasión ateniense:

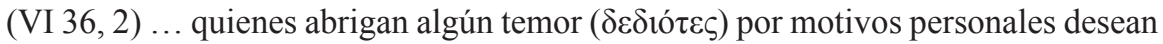
poner a la ciudad en un estado de pánico ( $\dot{\varepsilon} \varepsilon \tilde{\varepsilon} \kappa \pi \lambda \varepsilon \xi$ v) a fin de enmascarar su propio

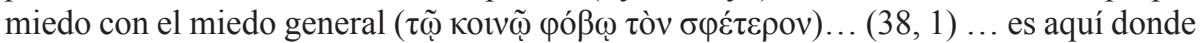
hay unos hombres que inventan historias que no existen ni pueden existir. (2) Yo me doy perfecta cuenta de que lo que estos hombres desean, no ahora por primera vez,

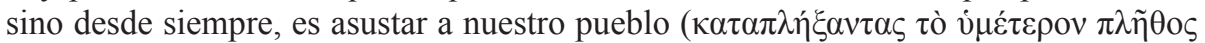
)... a fin de hacerse ellos con el dominio de la ciudad (cf. 40, 1-2).

¿Tal como anunciaba Diódoto, las sospechas de Atenágoras constituían una calumnia destinada a callar a Hermócrates? El lector sabe que la flota ateniense está aproximándose a Sicilia, pero desconoce si efectivamente en Siracusa había movimientos antidemocráticos y si los motivos de Hermócrates eran espurios y solo le interesaba aprovechar la circunstancia para promover cambios políticos. ${ }^{42}$ No obstante, aunque eso fuera así, no por ello dejaría de ser menos cierto que Siracusa debía tomar medidas frente a una inminente invasión; y que no tomarlas perjudicaría especialmente a los dirigentes demócratas. Si Hermócrates empezó a hablar subrayando su posición de debilidad, la actitud de Atenágoras confirmó sus recelos ya que su alocución nos hace pensar de nuevo en maniobras para silenciar a la minoría, especialmente con la amenaza de ser acusada de antidemócrata y antipatriota. El efecto de las palabras de Atenágoras -fueran mera calumnia o sospecha honesta- hubiera podido ser principalmente el de acentuar la sensación generalizada de pánico y aumentar la falta de confianza entre los ciudadanos; dicho de otro modo: obstruir la deliberación necesaria en esos momentos, la relativa a la invasión ateniense. El resultado hubiera podido ser el que ya conocemos en Atenas. En el caso de que los siracusanos se hubieran dejado llevar por el celo de Atenágoras, tal como los atenienses lo habían hecho por las palabras de Alcibíades, Siracusa hubiera podido ser tomada por sorpresa. Pero se impuso cierta sensatez que en el relato tucidídeo viene representada por la intervención escueta de un general anónimo que habló antes de cerrarse la sesión $(41,2)$. Ello indica que los siracusanos no se fiaron del todo de Atenágoras y, prudentemente, empezaron a prepararse y enviaron embajadas para pulsar el sentir de sus vecinos sicilianos (cf. 45).

42 Pero lo que sí es imposible es que el demos sepa quién miente, o como dice CALABrese (2008, 135-136) quién sabe y quién no sabe. Para la dificultad que tiene el demos en distinguir verdad de rumor, cf. Tsakmakis 2006, 167. 
Que el miedo no solo silencia las gargantas sino que también paraliza las mentes es algo que comprobamos con la lectura de los capítulos que describen en el libro VIII la situación de Atenas en la primavera de 411 a.C. cuando se impone el terror oligarca. La narración que hace Tucídides del momento se ha convertido en un clásico de la literatura sobre la acción terrorista y sobre la reacción psicológica que esta desencadena: desconocer cuál es la posición de los dirigentes y cuál el número de los implicados, no saber claramente qué está ocurriendo, la ausencia misma de un mensaje capaz de unir a los individuos, todo ello genera un miedo que se traduce en inacción y silencio. ${ }^{43}$ Los golpistas buscaron atemorizar para paralizar a quienes podrían haberse opuesto a sus planes. Y el miedo y la calma tensa hicieron su aparición, desintegrando a la comunidad, cuando Pisandro llegó a Atenas procedente de Samos, como emisario de los golpistas. Entonces fue convocada la asamblea a la que Pisandro comunicó que, contando con Alcibíades como valedor ante Tisafernes, los dirigentes atenienses en la flota de Samos estaban en situación de conseguir la ayuda persa con la que Atenas podría hacer frente exitosamente a Esparta. La condición sería hacer cambios políticos del gusto del Persa y, por tanto, modificar la democra-

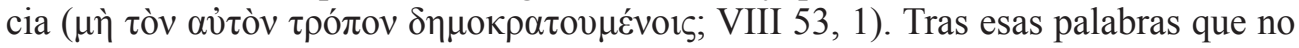
podían engañar a nadie, la asamblea prorrumpió en gritos de oposición. Aunque la descripción que hace el historiador del curso de esta asamblea no es muy detallada, podemos intuir que hablaron muchos políticos y que las masas reaccionaron espontáneamente contra la primera propuesta $(\S 2)$. Sin embargo Pisandro no se arredró, no perdió los papeles ni tuvo miedo de los oponentes, y fue preguntando uno a uno a los intervinientes si tenían alguna solución al problema real de que los lacedemonios en esos momentos tuvieran más recursos que ellos. Ante el mutismo general, un silencio que traduce desconcierto y temor, Tucídides dice que Pisandro "habló claro", lo que implicaría que la frase anterior -que también podrían traducirse como "gobernarse democráticamente de otra manera"- fue ya sustituida por términos como: "confiar el poder a unos pocos ciudadanos ... no deliberar ahora más sobre la forma de gobierno que sobre la salvación". Y resume Tucídides:

(VIII 54, 1). El pueblo, al escuchar estas palabras, aguantó mal al principio lo de la oligarquía, pero al explicarles Pisandro con toda claridad $(\sigma \alpha \varphi \tilde{\omega} \varsigma \delta 1 \delta \alpha \sigma \kappa o ́ \mu \varepsilon v o \varsigma)^{44}$ que

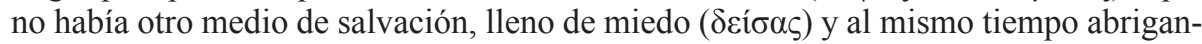
do la esperanza de una reforma ulterior, cedió.

En contraste con el discurso de Diódoto, Pisandro, a partir del segundo intento, habla muy claro, lo que quiere decir que no esconde ni las razones de su propuesta ni el verdadero objetivo. No por ello el demos deja de tener miedo: miedo por su incapacidad para oponer alternativas y miedo a lo que los cambios pueden acarrear. No obstante, se puede interpretar que todavía el temor inicial y el silencio con el que

43 ZuMbrunNen 2008, 32.

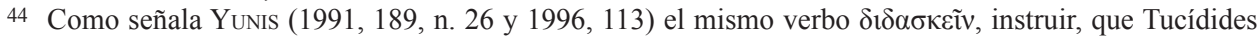
emplea para referirse a la oratoria de Pericles (II 40, 2; 60, 6). Sin embargo, McCoy $(1973,82)$ opina que Pisandro no habló claramente de oligarquía. 
la asamblea oye a Pisandro harían posible una toma de decisión racional. El pueblo compensa su ansiedad con una leve esperanza, porque así la situación resulta más aceptable para él: no se trata aquí del anhelo que empuja a empresas imprudentes, sino de la tímida expectativa que acompaña a los que sueñan pasivamente con tiempos mejores. En el fondo de la mencionada esperanza se oculta la resignación, y por esa vía se llega a la aceptación e inacción. De ahí la quietud que predomina en el marco público ateniense a partir de esos momentos.

Aunque Pisandro no habría ocultado la realidad sino que, como Tucídides se encarga de subrayar, "instruyó claramente" a los ciudadanos -y quizás tanto sobre la situación militar de Atenas como sobre los objetivos que movían a los que estaban en conexión con Alcibíades-, cuando este líder abandonó Atenas en la ciudad que-

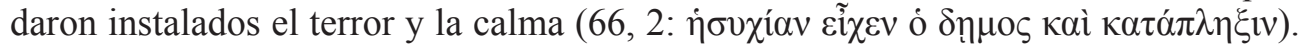
La asamblea, y el Consejo de los Quinientos, todavía se reunían, pero solo hablaban los conjurados y lo hacían con discursos supervisados por la dirección de las heterías oligárquicas $(\S 1)$. El desconocimiento y desconfianza hacían pensar a los ciudadanos comunes que los conjurados eran más de los que en realidad eran ( $(2)$, un fenómeno común cuando el mutismo de la mayoría permite que la expresión de una minoría organizada lo llene todo. El silencio, en esos casos, no es un silencio atento, sino receloso y cohibido. En realidad la palabra que resume la situación es la de terror y se trata de un estado emocional buscado conscientemente por los golpistas y preparado cuidadosamente mediante la puesta en escena de asambleas y juicios. Uno de los recursos empleados era amedrentar a los dirigentes: los asesinatos selectivos acallaban definitivamente la voces de los más habituados a hablar en la asamblea, y de rebote la mayoría se contentaba con salir ilesa a condición de mantenerse en silencio $(66,2$ : cỉ

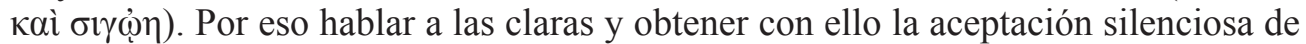
la asamblea no lo es todo en la línea de propiciar la deliberación prudente. Se requiere asimismo que la posibilidad de expresarse sea real para otros; y también cuenta el mensaje y los objetivos de quien habla. Pericles, como se ha visto, sabía cómo transformar los estados de ánimo de las multitudes y lo hacía para que el demos reflexionara prudentemente y asumiera la responsabilidad de sus decisiones. Pisandro, junto a la atención de sus oyentes, perseguía inculcar el miedo y la inacción. Por eso, tras la asamblea mencionada, lo que inundó Atenas no fue un estado de aceptación prudente sino un miedo paralizante que inducía la ausencia de pronunciamientos y la inactividad: la desintegración del pueblo en una masa desorganizada e incomunicada. ${ }^{45}$

La alternancia y el doble sentido que tienen el silencio y la agitación de las masas se percibe también cuando Alcibíades, repatriado por la flota ateniense que en Samos se mostró afín a la democracia, dejó claro que él poseía la capacidad de control sobre

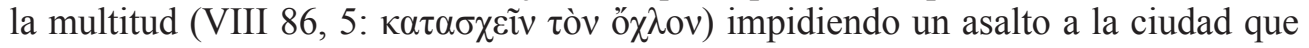
hubiera sido letal para los intereses de Atenas. A la llegada de los embajadores de los Cuatrocientos la masa náutica los recibió con los abucheos esperables $(86,2)$ pero que hacían inviable la comunicación. Solo cuando la asamblea fue acallada, y prestó

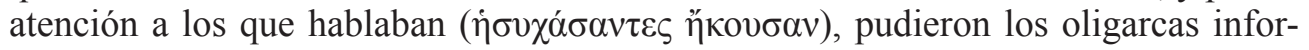

45 Por eso, explica McCoy (1973, 83-4), la asamblea descrita en Tucídides (VIII 67) aprobaría las resoluciones sin oposición. 
mar; y ello también hizo posible, a pesar de las falacias de su mensaje, que Alcibíades respondiera con un discurso que evitó el desastre que hubiera supuesto navegar al asalto de la propia ciudad. En el caso presente, el silencio condujo a la correcta deliberación y el político que supo establecerlo, y sustituir el griterío por el discurso, procuró el bien común.

\section{Conclusión}

En conclusión, la lectura de Tucídides nos indica que en Atenas ningún orador podía renunciar a crear en su audiencia el estado emocional que a su modo de ver mejor conviniera a los objetivos buscados. El temor, frecuentemente, pone a los colectivos que han de deliberar en la situación óptima para tomar la decisión más oportuna y beneficiosa para la ciudad. Y, en ese terreno, Pericles era imbatible por su habilidad para levantar el ánimo o bajar los humos al pueblo, atemorizado sin razón o ensoberbecido sin motivo. Su objetivo, en todo caso, era canalizar la correcta toma de decisiones. Pero los políticos también recurrían a amedrentar a sus rivales o a generar miedos en toda o parte de la audiencia cuando perseguían silenciar a una oposición que preveían capaz de impedir que triunfaran sus tesis. Ese obstruccionismo, que era fuente de desconfianza, es una táctica que aplicaron inicialmente los golpistas para acallar cualquier estorbo a sus propósitos. La práctica de deslegitimar la opinión contraria, según Diódoto (¡o Tucídides!), podría derivar de la incapacidad de algunos líderes para convencer persuadiendo honestamente. Los dirigentes oligarcas del 411 perfeccionaron esos modos: para ellos silenciar a los rivales pasaba por asesinar a los dirigentes, ocupar todo el espacio público, y quebrar la cohesión y confianza cívica.

Cuando una asamblea responde con griterío a la intervención de un orador, esa actitud no significa que todos los individuos que la integran hayan llegado a idéntica conclusión acerca de las propuestas del hablante, a la vez y de forma argumentada. Los mecanismos por los que las masas estallan de forma ruidosa y desordenada son conocidos y no suelen estar en relación con decisiones razonadas sino, más bien, con un contagio momentáneo e instintivo. En principio hay que sospechar de los usos obstructivos y reconocer que, si esta es la forma en que el demos se expresa, es una manera tan poco aceptable como el silencio y la inacción inducidos desde arriba a través del miedo.

En las democracias modernas sigue siendo un problema el canalizar las diferentes voces en aras, no de imponer una opinión única, sino de fomentar la correcta deliberación ciudadana. La reflexión ha de originarse necesariamente en el individuo, y estar guiada por el temor que deben inspirar los peligros reales de los que los políticos informan, pero no debería ser paralizada ni por amenazas y calumnias, ni por pánicos irracionales que inhiben el desarrollo correcto del debate político. 


\section{Bibliografía}

Balot, R. K. (2004): "Free Speech, Courage, and Democratic Deliberation", [en] Sluiter Rosen (eds.), 2004, 233-259.

BANFi, A. (2003): Il governo della città. Pericle nel pensiero antico, Napoli.

BAssi, K. (2007): “Spatial Contingencies in Thucydides' History”, ClAnt 26, 171-218 (http:// dx.doi.org/10.1525/ca.2007.26.2.171).

Bedford, D. - Workman, Th. (2001): “The Tragic Reading of the Thucydidean Tragedy", Review of International Studies 27, 51-67 (http://dx.doi.org/10.1017/S0260210500010512).

Calabrese, B. (2008): Fear in Democracy: A Study of Thucydides' Political Thought, Diss., University of Michigan.

CANFORA, L.

(1994²): Demagogia, Palermo.

(2014): El mundo de Atenas, Barcelona [trad. de E. Dobry de la ed. en Napoli, 2011, con graves errores].

Connor, W. R. (1971): The New Politicians of Fifth-century Athens, Princeton.

Cogan, M. (1981): The Human Thing. The Speeches and Principles of Thucydides' History, Chicago.

Demont, P. (1990): La cité grecque archaïque et classique et l'idéal de tranquillité (=Collection d'études anciennes 118), Paris.

Desmond, W. (2006): “Lessons of Fear: A Reading of Thucydides", ClPh 101, 359-379 (http:// dx.doi.org/10.1086/519183).

Edmunds, L. (1975): Chance and Intelligence in Thucydides (=Loeb Classical Monographs 11), Harvard-Cambridge (Mass).

FINLEy, M. I. (1962): “Athenian Demagogues”, P\&P 21, 3-24 (http://dx.doi.org/10.1093/ past/21.1.3).

GiRARD, CH. (2013): “Ce qu'Athènes apprend à la théorie politique. La démocratie est-elle un régime efficace? À propos de Josiah Ober, La Compétition, l'action collective et le problème du savoir utile", [en] Macé (éd.), 2013, 461-464.

Greenwood, E. (2004): "Making Words count: Freedom of Speech and Narrative in Thucydides", [en] Sluiter - Rosen (eds.), 2004, 175-195.

HuART, P. (1968): Le vocabulaire de l'analyse psycologique dans l'œuvre de Thucydide (=Études et Commentaires 69), Paris.

HunTER, V.

(1986): "Thucydides, Gorgias, and Mass Psychology", Hermes 114, 412-429.

(1988): "Thucydides and the Sociology of the Crowd", ClJ 84, 17-30.

Lafargue, Ph. (2013): Cléon. Le guerrier d'Athéna (=Ausonius Éditions, Scripta Antiqua 52), Bordeaux.

Lebow, R. N. (2007): “Thucydides and Deterrence”, Security Studies 16, 163-100 (http:// dx.doi.org/10.1080/09636410701399440).

Loraux, N. (1986): “Thucydide et la sédition dans les mots”, Q.St. 23, 95-134. 
MACÉ, A. (ÉD.), (2013): Le savoir public. La vocation politique du savoir en Grèce ancienne (=Cahiers de la Maison des Sciences de l'homme Ledoux 18; Série Normes, Pratiques et Savoirs 7), Besançon.

MacLeod, C. (1983): "Rhetoric and History (Thucydides 6, 16-18)", The Collected Essays of Colin MacLeod, Oxford, 68-86.

Manuwald, B. (1979): “Der Trug des Diodotos”, Hermes 107, 407-422.

MArA, G. M. (1993): “Cries, Eloquence, and Judgment: Interpreting Political Voice in Democratic Regimes", Polity 26, 155-187 (http://dx.doi.org/10.2307/3235027).

McCoy, W. J. (1973): “The "Non-Speeches" of Pisander in Thucydides, Book Eight", [en] Ph. Stadter (ed.), The Speeches in Thucydides. A Collection of Original Studies With a Bibliography, Chapell Hill, 78-89.

Mitchell, L. (2008): "Thucydides and the Monarch in Democracy", Polis (The Journal of the Society for Greek Political Thought) 25, 1-30 (http://dx.doi.org/10.1163/2051299690000123).

Mittelstadt, M. (1985): “The Thucydidean Tragic View: the Moral Implications", Ramus 14, 59-73.

Morgan, Th. E. (1994): "Plague or Poetry? Thucydides on the Epidemic at Athens", TAPhA 124, 197-209 (http://dx.doi.org/10.2307/284291).

Nagy, G. (2010): “The Subjectivity of Fear as reflected in Ancient Greek Wording”, Dialogues 5, 29-45.

OBER, J.

(1989): Mass and Elite in Democratic Athens. Rhetoric, Ideology and the Power of People, Princeton.

(1996): "The Nature of Athenian Democracy", The Athenian Revolution. Essays on Ancient Greek Democracy and Political Theory, Princeton, 113-122.

(2013): "La competition, l'action collective et le problème du savoir utile", [en] Macé (éd.), 2013, 365-401.

Patera, M. (2013): "Reflections on the Discourse of Fear in Greek Sources", [en] A. Chaniotis - P. Ducrey (eds.), Unveiling Emotions II. Emotions in Greece and Rome: Text, Images, Material Culture (=Habes 55), Stuttgart, 109-134.

RoIsman, J. (2004): “Speaker-Audience Interaction in Athens: A Power Struggle”, [en] Sluiter - Rosen (eds.), 2004, 262-275.

RomiLly, J. DE

(1956): “La crainte dans l'oeuvre de Thucydide”, $C \& M 17,119-127$.

(1977): "Les problèmes de la politique intérieure dans l'oeuvre de Thucydide", [en] Historiographia Antiqua. Commentationes Lovanienses in honorem W. Peremans septuagenarii editae, Leuven, 77- 93.

Rose, P. W. (2006): "Divorcing Ideology from Marxism and Marxism from Ideology: Some Problems", Arethusa 39, 101-136 (http://dx.doi.org/10.1353/are.2006.0006).

Saxonhouse, A. W. (2006): Free Speech and Democracy in Ancient Athens, Cambridge.

Shanske, D. (2007): Thucydides and the Philosophical Origins of History, Cambridge.

Sluiter, I. - Rosen, R. M. (eds.), (2004): Free Speech in Classical Antiquity (=Mnemosyne, Supplements 254), Leiden-Boston. 
Smith, D. G. (2004): “Thucydides' Ignorant Athenians and the Drama of Sicilian Expedition", SyllClass 15, 53-70 (http://dx.doi.org/10.1353/syl.2004.0005).

Solmsen, F. (1971): “Thucydides' Treatment of Words and Concepts", Hermes 99, 385-408.

Spina, L. (1986): Il cittadino alla tribuna. Diritto e libertà di parola nell' Atene democratica, Napoli.

Stahl, H. P. (1966): Thucydides. Die Stellung des Menschen im geschichtlichen Prozeß (=Zetemata 40), München.

TACON, J. (2001): "Ecclesiastic thorubos: Interventions, Interruptions, and Popular Involvement in the Athenian Assembly", $G \& R$ 48, 173-192 (http://dx.doi.org/10.1093/gr/48.2.173).

Tsakmakis, A. (2006): "Leaders, Crowds, and the Power of the Image: Political Communication in Thucydides", [en] A. Rengakos - A. Tsakmakis (eds.), Brill's Companion to Thucydides, Leiden-Boston, 161-187 (http://dx.doi.org/10.1163/9789047404842_008).

Verdenius, W. J. (1981): “Gorgias' Doctrine of Deception”, [en] G. B. Kerferd (ed.), The Sophist and their Legacy (=Hermes Einzelschriften 44), Wiesbaden, 116-128.

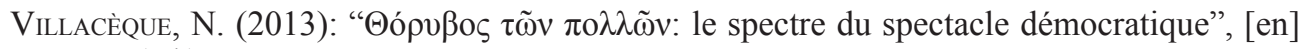
Macé (éd.), 2013, 287-312.

Visvardi, E. (2012): “Collective Emotion in Thucydides”, CHS Research Bulletin 1/1 (http:// wp.chs.harvard.edu/chs-fellows/2012/11/30/collective-emotion-in-thucydides-2/).

Wallace, R. (2004): “The Power to Speak -and not to listen- in Ancient Athens", [en] Sluiter - Rosen (eds.), 2004, 221-232.

Wensveen, J. (2013): Human Nature in Hobbes and Thucydides, Thes., Carleton University, Ottawa.

Yunis, $\mathrm{H}$.

(1991): "How do the People decide? Thucydides on Periclean Rhetoric and Civic Instruction", AJPh 112, 179-200 (http://dx.doi.org/10.2307/294717).

(1996): Taming Democracy. Models of Political Rhetoric in Classical Athens, Ithaca-London.

Zumbrunnen, J. (2008): Silence and Democracy. Athenian Politics in Thucydides' History, Pennsylvania. 